\title{
Article
}

\section{SYMBIOSIS: Development, Implementation, and Assessment of a Model Curriculum across Biology and Mathematics at the Introductory Level}

\author{
Audrey M. Depelteau, ${ }^{*}$ Karl H. Joplin, ${ }^{*}$ Aimee Govett, ${ }^{\dagger}$ Hugh A. Miller, III, \\ and Edith Seier ${ }^{\ddagger}$
}

Departments of *Biological Sciences, ${ }^{\dagger}$ Curriculum and Instruction, and ${ }^{\ddagger}$ Mathematics and Statistics, East Tennessee State University, Johnson City, TN 37601

Submitted May 17, 2010; Accepted June 23, 2010

Monitoring Editor: John Jungck

"It takes a lot of courage to release the familiar and seemingly secure, to embrace the new. But there is no real security in what is no longer meaningful. There is more security in the adventurous and exciting, for in movement there is life, and in change there is power."

Alan Cohen (Used by permission. All rights reserved. For more information on Alan Cohen's books and programs, see (www.alancohen.com.)

With the support of the East Tennessee State University (ETSU) administration and a grant from Howard Hughes Medical Institute, the departments of Biological Sciences, Mathematics and Statistics, and Curriculum and Instruction have developed a biology-math integrated curriculum. An interdisciplinary faculty team, charged with teaching the 18 curriculum modules, designed this three-semester curriculum, known as SYMBIOSIS. This curriculum was piloted to two student cohorts during the developmental stage. The positive feedback and assessment results of this project have given us the foundation to implement the SYMBIOSIS curriculum as a replacement for the standard biology majors curriculum at the introductory level. This article addresses the history and development of the curriculum, previous assessment results and current assessment protocol, and the future of ETSU's approach to implementing the SYMBIOSIS curriculum.

\section{INTRODUCTION}

In recent years, biology has been undergoing profound changes that are happening so quickly that biologists have not had the time to integrate these conceptual changes into intellectual and experimental frameworks (Dinger et al., 2009). Along with this increasingly rapid accumulation of data from research, biological education is not keeping pace with either conceptual or factual learning. Educational

DOI: $10.1187 /$ cbe.10-05-0071

Address correspondence to: Audrey M. Depelteau (depelteau@etsu.edu).

(C) 2010 A. M. Depelteau et al. CBE-Life Sciences Education (c) 2010 The American Society for Cell Biology. This article is distributed by The American Society for Cell Biology under license from the author(s). It is available to the public under an AttributionNoncommercial-Share Alike 3.0 Unported Creative Commons License (http://creativecommons.org/licenses/by-nc-sa/3.0). methodologies such as conceptual learning, hands-on learning, problem-based learning, and student-based learning have been recommended but are not universally implemented (Klymkowsky, 2005). One common theme throughout the literature is the need for increased instruction in quantitative biology (Brent 2004; Gross, 2004; Hoy, 2004). The BIO2010 report (National Research Council, 2003) emphasizes a more quantitative approach to teaching the biological sciences preferably at the introductory level. Additional calls for change are the suggested competencies for premed students and physicians (see the Association of American Medical Colleges [AAMC] and the Howard Hughes Medical Institute [HHMI] report [2009]), to be reflected in proposed changes to the Medical College Admission Test.

Since the advent of Project 2061 (American Association for the Advancement of Science, 1993), curriculum reform, student achievement, and the assessment of and improving 
student outcomes in the sciences has been a focus of $\mathrm{K}-12$ education and the accrediting commissions. If we want students to be successful in science, mathematics, and technology in higher education, we must shift from a professorcentered lecture paradigm to a student-centered learning paradigm (Harkness, unpublished, paper at 101st American Political Science Association Annual Conference, Washington, DC). The driving force behind the development of the SYMBIOSIS integrated biology-mathematics curriculum was our vision of students having an authentic science experience.

A small cohort of students, recruited for a National Science Foundation-Science, Technology, Engineering, and Mathematics Talent Expansion Program (NSF-STEP) grant, were the pilot group for the initial implementation of the three-semester integrated curriculum. The first semester (Symbiosis I: Biology and Statistics) also has been taught for the State of Tennessee Governor's School: Scientific Models and Data Analysis summer program since 2008. Designing of the curriculum material and the preand posttest concept questions was a concerted effort of faculty from the departments of Biological Sciences, Mathematics and Statistics, and Curriculum and Instruction. The results of these assessments demonstrated that the SYMBIOSIS material could be used in introducing college and precollege students to an integrated approach to quantitative biology. A large-scale assessment protocol has been developed to establish a baseline of the effect of instruction on biology students' understanding of integrated biology and mathematical concepts using the traditional biology curriculum as a comparison to the SYMBIOSIS curriculum.

\section{DEVELOPMENT OF SYMBIOSIS CURRICULUM}

Although a review of funded grants shows most programs develop integrated courses at the junior, senior, and graduate levels, we developed an integrated curriculum for the introductory level. During this initial development (20052006), the departments received an NSF-STEP grant allowing us to recruit freshmen as a logical pilot group to take the integrative courses.

Each SYMBIOSIS module includes the biology concept(s) and the math skills needed to analyze data sets that examined the concepts. A 2-wk laboratory, one for collecting data and the other for analyzing data, were developed for each module. The availability of data sets to support specific biology concepts became our overriding criteria. To match the current biology and math curriculum (www.etsu.edu/ $\mathrm{reg} / \mathrm{catalog} /$ undergraduate.aspx), the courses were designed to contain $5 \mathrm{~h}$ of lecture and $2 \mathrm{~h}$ of laboratory each week.

Many graduate and professional schools are not currently set up to recognize integrated courses as meeting the admission requirements. It was therefore critical that the names of these courses reflect the content on the students' transcripts. The courses were named as follows: Integrated Biology and Statistics, Integrated Biology and Calculus, and Integrated Biology and Discrete Math, and a separate rubric (IBMS) for the courses was obtained. The curriculum committee also worked with the East Tennessee State University (ETSU)
Quillen College of Medicine admission committee and the Office of Medical Professions Advisement at ETSU to ensure that the application process through the American Medical College Application Service recognizes the course content in the integrated curriculum.

Once the initial logistics were complete, faculty from math and biology submitted an HHMI educational grant with the vision to create a three-semester introductory curriculum of integrated biology/math where the student would receive credit for three semesters of introductory biology for majors, a semester of statistics, and a semester of calculus. The course was presented as a 6-credit course for each of the three semesters. The 4-yr grant was funded in fall 2006, and the course was first taught in fall 2007.

\section{SYMBIOSIS CURRICULUM}

As in many institutions, our standard biology for majors curriculum involves a large lecture format (sections of $\geq 300+$ students) and smaller lab sections of 25 students. The material has largely been based on a typical textbook in terms of content but seems to promote passive learning with superficial retention of the material and little integration of conceptual learning (Armbruster et al., 2009).

SYMBIOSIS is a unique approach where each semester is made up of six 2-wk modules defining both the biology and mathematics or statistical material. Each module consists of $10 \mathrm{~h}$ of classroom and two 2-h labs consisting of an experimental and analytical lab. A team consisting of at least two faculty members, a biologist and a mathematician or statistician, developed and team-taught each module. Over time, the faculty has become more comfortable with each other's field. Statistics and biology make a relatively easy pairing, both conceptually, as well as operationally (Joplin et al., 2010).

Modern biology pedagogy is based, to a large extent, on a pseudological framework of going from small-to-big and is rooted in what biology has done rather than why or how it is done (Moore et al., 2010). An examination of modern biology textbooks supports this contention because they are not quantitative and are primarily encyclopedic in content with very little integration of material between chapters. Noticeably missing are equations, data sets, and graphs, which demonstrate the richness of variation that is a major component of biology. In traditional pedagogy, this lack of quantitative analysis leads the student to be bombarded with an unending series of facts that have no logical connection to the whole. Could this old approach be one reason why professors have observed that students retain little introductory material in upper-level courses (Bransford et al., 2000; Armbruster, 2009)?

A literature search reveals very little development of an integrated math biology curriculum at the introductory level. The criteria that have guided the development of the statistical component of the first semester of SYMBIOSIS are as follows: an early introduction of inference to be able to answer research questions from the beginning, examples of the sequence rationale-algorithm-computer program, use of a problem-oriented approach presenting statistical methods when they are needed, emphasis on the study of variability, emphasis on a multivariate view whenever possible, and 
inclusion of topics at the elementary level that can serve as a preparation to later understand the language and methods of biostatistics/bioinformatics, including exposure to statistical software. Active learning and critical thinking are promoted through class discussion and activities, homework, and assignments. The statistical analysis of real biological data drives the students into discovering facts instead of listening to facts passively.

A complete description of the material in the curriculum is beyond the space of the article. The following are abbreviated descriptions of the topics covered. A longer version can be found at our website at www.etsu.edu/cas/symbiosis/ default.aspx. A short description of model I in Symbiosis I is presented with the remainder modules just outlined.

In Symbiosis I, students start with the scientific method (Module I) and statistical hypotheses testing during the first week of the course, even though the classical topics of sampling distributions have yet not been covered. This was just the first example of how we have adjusted course material by using randomization methods (permutations test) to test hypotheses about the means of two populations. To test hypotheses about a population proportion, basics of probability and the binomial distribution are introduced and the exact test appears as a simple application of the binomial distribution. The scientific method is taught using case studies such as von Helmont's tree growing experiment, Stanley Pruissner's development of the prion theory, the methodology of identification of mosquito vectors of arboborne diseases, introduction of human immunodeficiency virus (HIV) as the etiology of AIDS, before asking the question as a class project of whether mosquitoes could transmit HIV. The answer to this question is the use of statistics to look at the Bel Glade study in Florida by using epidemiology (Centers for Disease Control and Prevention, 1986). The module ends with a description of the five basic concepts of biology: evolution; membrane-bound cellular organization; energy metabolism; response to the environment; and growth, reproduction, and development. Each of these concepts is explicitly covered in each of the modules that maintain a connection between the topics of the course.

Module II covers the cell by using data sets of abnormal and normal cells; red blood cell counts; and the dimensions of cells to introduce descriptive statistics, including correlation and statistical graphs. The study of relationships between variables is extended by the study of functions by using scaling to study allometry and isometry (Module III). Genetics and probability (Module IV) are also a natural fit because copying alleles from parents to offspring involves randomness and provides a perfect motivation for the study of probability, along with conditional probability, independence, and the corresponding test of independence. DNA genetics (Module V) and introductory bioinformatics (Module VI) provides the opportunity to apply probability and testing hypotheses to molecular biology, such as calculating the probability of sequences in DNA data sets. Classic topics of statistical inference (e.g., confidence interval estimation, test of hypotheses for proportions using large samples, $t$ tests) from introductory statistics also are included. These methods are used to compare mitochondrial sequences of insect species with the Drosophila mitochondria as a refer- ence. The students discuss the differences between species at the DNA level.

In the following semester, Symbiosis II, the mathematical topics focus mainly on calculus with a minor statistical component. The biological topics were rearranged from our normal progression to use rate of change for the calculus. The models are as follows: populations, ecology, behavioral ecology, chronobiology, structured populations, energy, and enzymes. One of the goals of the SYMBIOSIS project is to cover a first-semester calculus course by the end of Symbiosis II. Thus, the calculus in Symbiosis II is actually a continuation of math concepts begun in Symbiosis I.

A student who successfully completes Symbiosis I and II will have covered all the topics that constitute a rigorous, sciences majors' statistics and calculus course. The coverage of calculus has been extended across two semesters, allowing students to acclimate to the calculus at a more deliberate pace than they would in other calculus courses. In addition, the overwhelming majority of the calculus that is covered is introduced and developed in contexts that are important to the study and practice of biology. The result is a symbiotic relationship between calculus and biology-biology benefits from the rich variety of analytical models that calculus permits, whereas calculus benefits from the rich variety of settings and motivations that biology provides. Moreover, weaker students benefit from having an entire year to study material that is typically covered in a one-semester course.

The mathematics component is assessed by the students taking the Math Department's Gateway exam that demonstrates competency in calculus concepts to receive credit for the calculus course. Successful passage of this exam is required for students to take Calculus II. All of the SYMBIOSIS students who have taken this exam have passed the Gateway exam.

In Symbiosis III, the emphasis of the quantitative component includes calculus; matrices; graph theory; and advanced statistical topics such as nonlinear estimation, multivariate methods, and an introduction to bioinformatics. The biological topics are neurons, membranes, developmental biology, and bioinformatics.

\section{CURRICULUM IMPLEMENTATION OF COUPLED COURSES}

Transitioning from class sizes of $<20$ in the pilot study to multiple sections of 250-300 for biology and 50-75 for math and statistics means adopting a different pedagogical approach. The recognized challenges include the large block of time required, the faculty load/credit assignment issues, and the differences in instructional necessities. The first two semesters of biology will be taught using the SYMBIOSIS integrated material with specifically designed mathematics and statistics courses as corequisites. Thus, Symbiosis I modules will be taught as Biology I (IBMS 1110) and Statistics (IBMS 1530) in the first semester. Symbiosis II modules will be taught as Biology II (IBMS 1120) and Calculus (IBMS 1910) in the second semester. Symbiosis III (IBMS 1130) modules will maintain the integrated approach during the third semester. The mathematics component in IBMS 1130 is an extension of differential and integral calculus, introduc- 
Table 1. Matching the SYMBIOSIS modules to the list of competencies (E) for premedical undergraduate students with the HHMI-AAMC report (2009)

\begin{tabular}{|c|c|c|c|}
\hline AAMC-HHMI competencies & Symbiosis 1 & Symbiosis 2 & Symbiosis 3 \\
\hline $\begin{array}{l}\text { E1. Quantitative reasoning: Get specific, "apply quantitative reasoning and appropriate } \\
\text { math to describe or explain phenomena in the natural world." }\end{array}$ & $1-6$ & $1-6$ & $1-6$ \\
\hline E2. Scientific inquiry & \multicolumn{3}{|c|}{ All laboratory experiments and data analysis } \\
\hline E3-1, $-4,-6$. Physical principles; thermodynamics & & 6 & 2 \\
\hline E4. Chemistry of living systems & & 4 & $1,3,5,6$ \\
\hline E5. Cell structure and biomolecules & $2,4,5$ & 6 & $1,3,4,5,6$ \\
\hline E6. Organismal hierarchy & 3 & 1,3 & 4 \\
\hline E7. Response to internal and external signals & 2 & $1-5$ & $1,2,4$ \\
\hline E8. Evolution by natural selection & $4-6$ & & \\
\hline
\end{tabular}

Numbers $1-6$ in table body represent the module number.

tion to linear algebra, and matrices and analysis of variance (ANOVA).

This approach maintains our commitment to an integrated presentation of biology, statistics, and mathematics. To maintain this integration, regularly scheduled meetings of the entire instructional team will be held to ensure all faculty, instructors, and lab instructors are staying on track with the course and lab materials.

Recently, HHMI-AAMC published a set of learning competencies for premedical students (2009). Our curriculum was developed and piloted before this list was published. Careful consideration of the objectives of the SYMBIOSIS modules enabled us to map the modules to these competencies (Table 1).

The first set of competencies (E1) concerns demonstration of quantitative skills to data analysis. A major component of our curriculum involves students examining data sets by using statistical skills. Students participate in data analysis in both the classroom and laboratory. In one example, of the cell module, students are introduced to data related to the cell area of erythrocytes in birds (www. genomesize.com/cellsize). Students use these data to learn approaches to data visualization as well as supporting concepts related to cell volume, cell size, and species variation. Pedagogical approaches such as these are used throughout the SYMBIOSIS curriculum to assist students in developing higher-level thinking skills (Bloom, 1956; Metz, 2008). These problem-solving opportunities support several learning objectives outlined under competency E1 (pages 22 and 23) in the HHMI-AAMC report. This is significant because a large proportion of ETSU students who enroll in the freshman biology program are preprofessional, many destined for a career in medicine. These competencies and objectives will serve as a guide and framework for us using a backward design and teaching for understanding (Wiggins and McTighe, 2005) approach in the ongoing development of this curriculum. In the evolution of the SYMBIOSIS curriculum, we are committed to having students learn how biologists do science by focusing on having students develop critical-thinking skills (context) and in becoming intentional learners as they collect and analyze data and model biological systems (process). This takes a nonlinear approach to biolog- ical and math material away from concentrating solely on the content material.

\section{PREVIOUS ASSESSMENT RESULTS}

In fall 2007, a group of students took the interdisciplinary Biology and Mathematics \& Statistics course, SYMBIOSIS I consisting of Modules 1-6, with wet and dry labs to reinforce concepts as well as to develop and apply analytical skills. As an institutional review board (IRB)-approved study, students were tested on biology concepts and mathematics/statistics skills before and after each module. The pretest questions, with identical wording and format, were imbedded in each module exam. Overall, their scores increased from $30.9 \%$ for the pretests to $71.33 \%$ for the posttests. The gain $(\mathrm{g})$ for statistics concept questions was 0.56 , and the $g$ for the biology items was 0.61 (Table 2). Similar results were obtained for cohort 2 in fall 2008 as detailed below.

A similar curriculum was taught for the East Tennessee State University Governor's School: Scientific Models and Data Analysis during summer 2009. Their scores increased from a mean of $34 \%$ for the pretests to a mean of $65 \%$ for the posttests for the subset of concept questions.

In spring 2008, a comprehensive concept pretest to cover modules 7-12 in the interdisciplinary course SYMBIOSIS II was developed. These items were identified as either predominantly math, predominantly biology, or as truly integrated conceptually. The final for this course included 33 of the items from the pretest and were used in the analysis. The

\begin{tabular}{llccc} 
Table 2. Assessment of SYMBIOSIS I & & \\
\hline Cohort & $\begin{array}{c}\text { Symbiosis I } \\
(\text { modules 1-6) }\end{array}$ & $\begin{array}{c}\text { Pretest } \\
\text { score (\%) }\end{array}$ & $\begin{array}{c}\text { Posttest } \\
\text { score (\%) }\end{array}$ & $\begin{array}{c}\text { Normalized } \\
\text { gain }\end{array}$ \\
\hline 1 & Statistics & 27.0 & 68.1 & 0.56 \\
& Biology & 34.8 & 74.5 & 0.61 \\
2 & Combined & 30.9 & 71.3 & 0.59 \\
& Statistics & 26.3 & 66.1 & 0.54 \\
& Biology & 27.3 & 70.5 & 0.59 \\
& Combined & 26.8 & 68.3 & 0.57 \\
\hline
\end{tabular}




\begin{tabular}{lcccc}
\hline \multicolumn{6}{l}{ Table 3. Assessment of SYMBIOSIS II } & & \\
\hline Cohort & $\begin{array}{c}\text { Symbiosis II } \\
\text { (modules 7-12) }\end{array}$ & $\begin{array}{c}\text { Pretest } \\
\text { score (\%) }\end{array}$ & $\begin{array}{c}\text { Posttest } \\
\text { score (\%) }\end{array}$ & $\begin{array}{c}\text { Normalized } \\
\text { gain }\end{array}$ \\
\hline 1 & Integrated & 28.6 & 83.1 & 0.76 \\
& Math & 26.3 & 65.7 & 0.53 \\
& Biology & 27.3 & 43.6 & 0.23 \\
2 & Combined & 27.7 & 66.2 & 0.53 \\
& Integrated & 58 & 85 & 0.67 \\
& Math & 19 & 56 & 0.44 \\
& Biology & 16 & 44 & 0.33 \\
& Combined & 31 & 62 & 0.51 \\
\hline
\end{tabular}

scores for the biology concept questions increased from 27.3 to $43.6 \%$, the scores for the predominantly math items increased from 26.3 to $65.7 \%$, and the scores for the integrated items increased tremendously from 28.6 to $83.1 \%$ for a normalized $g$ of 0.76 . Combined scores went from $27.7 \%$ for the pretest to $66.2 \%$ for the posttest (Table 3 ). Similar results were obtained for cohort 2 in spring 2009 as shown in Table 3.

The first cohort continued their interdisciplinary biology program with the six modules of SYMBIOSIS III in fall 2008; it consisted of lecture units with wet and dry labs to reinforce concepts (Table 4).

The test items along with the curriculum were developed by the teaching faculty. To substantiate these gains as being significant, we have developed an assessment tool that will allow us to compare SYMBIOSIS students with students completing the current, more traditional curriculum.

\section{CURRENT ASSESSMENT PROTOCOL}

In a project of this scope, assessment is a major consideration to decide if the results of the SYMBIOSIS project are an improvement to students' conceptual learning over the standard curriculum. The general purposes of assessment vary from attempting to measure how well students are learning content material to assessing teaching pedagogy to improve teaching effectiveness. The pretest-posttest assessment has been widely used across many disciplines to measure basic course knowledge of core concepts and course objectives. Although it is evident that the pretest-posttest assessments can demonstrate evidence of course content learning and assess instructional effectiveness, it also measures entering student preparedness for course material. Furthermore, the instrument can be used to assess knowledge retention from sequential course prerequisites (S.J. Harkness, 2005, unpublished results).

Table 4. Assessment of SYMBIOSIS III

\begin{tabular}{llccc}
\hline Cohort & $\begin{array}{c}\text { Symbiosis III } \\
\text { (modules 13-18) }\end{array}$ & $\begin{array}{c}\text { Pretest } \\
\text { score (\%) }\end{array}$ & $\begin{array}{c}\text { Posttest } \\
\text { score (\%) }\end{array}$ & $\begin{array}{c}\text { Normalized } \\
\text { gain }\end{array}$ \\
\hline 1 & Mathematics & 13 & 58 & 0.52 \\
& Biology & 28 & 71 & 0.60 \\
& Combined & 20.5 & 64.5 & 0.55 \\
\hline
\end{tabular}

Our multifaceted plan has the unique opportunity to collect a large data set from the standard lecture-based introductory biology courses over a 2-yr period. It is important to note that perhaps the best way to address the shortcomings of a pre-,mid-, and posttest study is to use a control group (Colosi and Dunifon, 2006). Several cohorts of the ETSU biology (IBMS 1110, 1120, 1130) students, beginning in 2009, have been used as a comparison group. These courses will be compared with the SYMBIOSIS (IBMS 1110, 1130, 1120) courses beginning in the 2011 school year. Although this aspect was not envisioned in our initial objectives, it will be a landmark assessment study in biology curriculum development considering the inclusion of the large comparison group. We anticipate assessing $>5000$ students during this 4-yr study.

The purpose of this protocol is to investigate the effect of instruction on biology students' understanding of integrated biology and mathematical concepts in both the traditional biology curriculum and the implemented SYMBIOSIS curriculum. To avoid the danger of assessment pushing teaching and learning in undesirable directions that are counterproductive (Britton and Schneider, 2007), the instructor of record does not and will not have access to the assessment items. This program is an ETSU IRB approved protocol with no known associated risks to the participants, and all members of the interdisciplinary assessment team are Collaborative Institutional Training Initiative trained.

The assessment test consists of 60 multiple-choice questions, with $\sim 20$ questions applicable to each of the three semesters. Multiple-choice questions are advantageous in a large-scale study of this nature for efficiency reasons, especially because we are doing an item analysis of each question. In our desire to create a test that measures higher-level objectives, we followed the following steps: use of questions with a variety of answer types, e.g., moving away from single answer to multiple response to combined response; and use of questions that included functional distractors to make them more complex than routine questions. A pool of several hundred questions written by the interdisciplinary team was reviewed to choose the top 100 most appropriate questions that ran the scope of the curricular material. From this pool of 100 questions, 20 questions relating to each of the three semesters was chosen to produce the 60 -item assessment test. These items are unique to the curriculum and also there is no standardized pool of biology concept questions in the research literature, especially at the quantitative level for introductory biology. To find the reliability of this 60 -item multiple-choice test (55 questions have five alternative answers; four questions have four alternative answers; and one question has two alternative answers), we determined the probability of scoring $70 \%$ or higher by guessing alone. This probability is very small $(\sim 2.717011 \mathrm{e}-16)$.

Data collection, Rausch analyses, computation of scale scores, and statistical tests ( $t$ tests, ANOVAs, analyses of covariance, and normalized gain) will be used to determine students' changes in content knowledge. The inherent difficulty with raw scores is that not all of the items are equally difficult. A student who correctly answers the five hardest items on a test probably knows more than the student who answered the five easiest items correctly. To address this issue, several scaling methods can be used, the most well known being the Rausch model. The Rausch item analysis 
will be used to allow the calculation of a scale score for a more meaningful and rigorous comparison of student abilities as measured with this particular test. Other parameters include pre- and postcourse surveys such as the SURE III, SURE Follow Up Survey, CURE projects of the Grinnell Model (www.grinnell.edu/academic/psychology/faculty/ $\mathrm{dl}$ /sure\&cure), in-class clicker technology, and self-assessment journals. We would also like to investigate demographic and gender differences in large-scale assessments.

\section{CONCLUSIONS}

In higher education, there are no empirical data showing student gains from integrated mathematics and science curriculum projects. Achieving successful curricular change was driven by our willingness to embrace the vision of BIO2010. During the development of the courses, we came to the conclusion that the approach of teaching biology with math has greatly added to the conceptual richness of biology instruction while giving the math a contextual basis for instruction. Our ability to distinguish and overcome obstacles and our willingness to be open-minded, along with cooperation, communication, and collaboration, were essential to the success of the program.

The new curriculum is a shift from the secure and familiar traditional educational methodologies to a more studentcentered approach. The complete six-phase, multiyear project covers a lot of material and will be one of the most complete, controlled comparisons of teaching methodology that has been reported. The assessment protocol will provide the teaching faculty in biology and mathematics with valuable information on current curriculum and teaching practices compared with the efficacy of the SYMBIOSIS curriculum, document student achievement of learning outcomes, and identify effective and ineffective practices. As such, the departments will be able to direct the necessary resources and interventions that will ensure the success of the implementation of the SYMBIOSIS curriculum.

\section{REFERENCES}

American Association for the Advancement of Science (1993). Project 2061, Benchmarks for Science Literacy, New York: Oxford University Press.

Armbruster, P., Patel, M., Johnson, E., and Weiss, M. (2009). Active learning and student-centered pedagogy improve student attitudes and performance in introductory biology. CBE Life Sci. Educ. 8, 203-213.

Association of American Medical Colleges and Howard Hughes Medical Institute (2009). Scientific Foundations for Future Physicians, Washington, DC.

Bransford, J. D., Brown, A. L., and Cocking, R. R. (2000). How People Learn: Brain, Mind Experience and School, Washington, DC: National Academies Press.

Britton, E. D., and Schneider, S. A. (2007). Large-scale assessments in science education. In: Handbook of Research on Science Education, ed. S. K. Abel and N. G. Lederman, Mahwah, NJ: Lawrence Erlbaum Associates Publishers, 1007-1040.

Brent, R. (2004). Intuition and innumeracy. Cell Biol. Educ. 3, 88-90.

Bloom, B. S. (1956). Taxonomy of Educational Objectives, Handbook I: The Cognitive Domain, New York: David McKay.

Centers for Disease Control and Prevention (1986). Epidemiologic Notes and Reports Acquired Immunodeficiency Syndrome (AIDS) in Western Palm Beach County, Florida. MMWR 35, 609-612.

Colosi, L., and Dunifon, R. (2006). What's the difference? "Post the pre" \& pre then post, Ithaca, NY: Cornell Cooperative Extension.

Dinger, M. E., Amaral, P. P., Mercer, T. R., and Mattick, J. S. (2009). Pervasive transcription of the eukaryotic genome: functional indices and conceptual implications. Brief. Funct. Genomics Proteomics 8, 407-423.

Gross, L. J. (2004). Interdisciplinarity and the undergraduate curriculum: finding a balance. Cell Biol. Educ. 3, 85-87.

Hoy, R. (2004). New math for biology is the old new math. Cell Biol. Educ. 3, 90-92.

Joplin K. H., Seier, E., Godbole, A., Helfgott, M., Karsai, I., Knisley, J., Moore, D., and Miller H. A., 3rd (2010). SYMBIOSIS: an integration of biology and statistics at the freshman level: walking together instead of on opposite sides of the street. MAA Notes (in press).

Klymkowsky, M. W. (2005). Can nonmajors' courses lead to biological literacy? Do major courses do any better? Cell Biol. Educ. 4, 196-198.

Metz, A. M. (2008). Teaching statistics in biology: using inquirybased learning to strengthen understanding of statistical analysis in biology laboratory courses. CBE Life Sci. Educ. 7, 317-326.

Moore, D., Helfgott, M., Joplin K., Karsai, I., Knisley, J., and Seier, E. (2010). The SYMBIOSIS project: current and future needs. MAA Notes (in press).

National Research Council (2003). BIO2010: Transforming Undergraduate Education for Future Research Biologists, Washington, DC: National Academies Press.

Wiggins, G., and McTighe, J. (2005). Understanding by Design. Alexandria, VA: Association for Supervision and Curriculum Development. 